\title{
Red meat and colon cancer: \\ Should we become vegetarians, or can we make meat safer?
}

\author{
Denis E. Corpet \\ Université de Toulouse, ENVT, INRA, UMR1331 Toxalim, BP-87614, 23 Capelles, F-31076 Toulouse, France
}

\begin{abstract}
The effect of meat consumption on cancer risk is a controversial issue. However, recent meta-analyses show that high consumers of cured meats and red meat are at increased risk of colorectal cancer. This increase is significant but modest (20-30\%). Current WCRF-AICR recommendations are to eat no more than 500g per week of red meat, and to avoid processed meat. Moreover, our studies show that beef meat and cured pork meat promote colon carcinogenesis in rats. The major promoter in meat is heme iron, via $\mathrm{N}$-nitrosation or fat peroxidation. Dietary additives can suppress the toxic effects of heme iron. For instance, promotion of colon carcinogenesis in rats by cooked, nitrite-treated and oxidized high-heme cured meat was suppressed by dietary calcium and by $\alpha$-tocopherol, and a study in volunteers supported these protective effects in humans. These additives, and others still under study, could provide an acceptable way to prevent colorectal cancer.
\end{abstract}

Key Words: Red meat, processed meat, safer meat, colon cancer, epidemiology, heme iron

\section{Introduction}

Is it safe to eat meat? The news media reports that meat causes cancer, each time a new scientific study is published. Is the causal link truly demonstrated, or is it only a speculative assumption? Anyway, current recommendations take this risk in account: To reduce the risk of cancer, the 2007 report of the World Cancer Research Fund makes the recommendation to limit the consumption of red meat and to avoid processed meat intake (World Cancer Research Fund \& American Institute for Cancer Research, 2007). Based on this report, the French National Cancer Institute recommends: "Limit intake of red meat to less than $500 \mathrm{~g}$ per week. Limit intake of cured meats, especially high fat or very salty ones. Those who eat cured meat should choose it less often and reduce portion size." (INCa \& NACRe, 2009). If these recommendations were adhered to, cancer incidence may be reduced, but farmers and meat industry would suffer important economical problems, while the impact of meat on the risk of cancer is a controversial topic (Demeyer, Honikel, \& De Smet, 2008; Parnaud \& Corpet, 1997; Santarelli, Pierre, \& Corpet, 2008). Although meat intake is not the only risk factor for colorectal cancer, the aim of this article is to focus on meat, to review epidemiological and experimental data and to report recent rodent studies pointing to possible solutions.

\section{Colorectal cancer: Epidemiological studies}

\section{1- Correlation studies, case-control studies, cohort studies.}

Correlation between cancer mortality and diet is remarkably strong at the international level: colorectal cancer is frequent in Western countries were red meat is frequently consumed; in contrast, this type of cancer is rare in less affluent countries where meat intake is low ( $\mathrm{S}$. Bingham \& Riboli, 2004). However, correlation is not causation, and it is clear that many other lifestyle factors are different in affluent and poor countries. The hypothesis that red meat favors cancer must be tested at the individual level. Nearly one hundred publications report a link between meat intake and colorectal cancer risk, most of them being retrospective case-control studies, some of them prospective cohort studies. In a retrospective study, people are asked on their past diet, and the answers of hundreds of cancer patients are compared to those of noncancer paired controls. However, the estimation of foods consumed years before is inaccurate, and cancer changes memories, which biases case-control comparison. In addition, results can 
change depending of the chosen controls, which casts doubts on retrospective studies conclusion. Cohort studies are much longer and more expensive, but they avoid these limitations: thousands to million of healthy people are questioned on their current diet and lifestyle. The cohort is followed for ten to twenty years, and occurring diseases are registered. The statistical link between current diseases and past food intake can then be searched for. One case-control study out of three, and one cohort study out of five, shows a significant link between colorectal cancer risk and red meat or processed meat intake (Norat \& Riboli, 2001).

\section{2-Major meta-analyses on meat and cancer}

In order to estimate the risk associated with meat intake, all of these studies were gathered in two major meta-analyses, whose major results are reported below (Larsson \& Wolk, 2006; Norat, Lukanova, Ferrari, \& Riboli, 2002). A metaanalysis is a statistical approach that gathers all data from published epidemiological studies, after exclusion of poor quality studies. Theoretically, the global result is equivalent to a single large study including all the subjects of the original studies. Due to the very high number of included subjects, even relative risks that are not far from one may be significant. In addition it enables the study of sub-groups that were too small to be analyzed in the original studies.

Norat's meta-analysis gathers 23 cohort and case-control studies, selected out of 48 studies by using pre-established quality criteria (Norat, et al., 2002). Larsson's meta-analysis gathers 18 prospective studies selected out of 23 , aggregating more than one million subjects (Larsson \& Wolk, 2006). Both meta-analyses are rather independent from each other, because subjects included in Norat's study make only 15\% of Larsson's one. The WCRF-AICR 2007 report also describes a meta-analysis based on original studies already included in Larsson's study, and whose results are very close to Larsson's ones. These three meta-analyses bring global and consistent conclusions for different types of meat: total meat intake, red meat, processed meat, and poultry meat. "Red meat" and "processed meat" definitions are tricky points, since it does not mean the same thing in all studies. In most publications, "red meat" gathers beef, veal, mutton, pork and offal, and "processed meat" (equivalent: deli meat) gathers cooked, dried, smoked, or cured meat and offals from any animal, but mostly pork. Some studies make a distinction between fresh and processed meat.

\section{3- Major results of meta-analyses}

Major results of Norat's and Larsson's metaanalyses were reported as follows:

- Consumption of total meat (all types of meat) is not associated with colorectal cancer risk.

- Consumption of "red meat" is associated with a moderate risk increase:

$=$ Norat reports a relative risk $(\mathrm{RR})$ of colorectal cancer of 1.35 for the quartile of people eating the highest amount of red meat (including processed meat). It means that cancer risk increased by $35 \%$ compared with the quartile eating the least red meat. The $95 \%$ confidence interval $(95 \% \mathrm{CI})$ is $1.21-1.51$ and does not include "one", telling the increase is significant. After exclusion of processed meat, the risk associated with eating $120 \mathrm{~g} / \mathrm{d}$ fresh red meat was still significant $(+19 \%)$ (Norat, et al., 2002).

$=$ Larsson reports a colorectal cancer RR of $1.28(95 \%$ CI $1.15-1.42)$ for the high red meat eaters (including processed meat). Intake of fresh red meat (excluding processed meat) was reported in nine studies out of 15 , and the associated RR is 1.22 (significant). The risk associated with eating $120 \mathrm{~g} / \mathrm{d}$ of red meat is $+28 \%$. Larsson's analysis is less detailed than Norat's: dose-effect was not calculated specifically for fresh red meat, and some points remain obscure (e.g., meat categories) (Larsson \& Wolk, 2006).

$=$ The WCRF 2007 report gives a summary effect estimate RR of 1.29 (95\% CI 1.04-1.60) for $100 \mathrm{~g} /$ day from only three selected original studies (World Cancer Research Fund \& American Institute for Cancer Research, 2007).

- Consumption of processed meat (mostly deli or cured meat) is associated with colorectal cancer risk: highest vs. lowest category RR are 1.31 (95\%CI 1.13-1.51) and 1.20 (95\%CI 1.11-1.31) in those two studies respectively (Larsson \& 
Wolk, 2006; Norat, et al., 2002). The WCRFAICR reports a summary effect estimate of 1.21 (95\%CI 1.04-1.42) for $50 \mathrm{~g} /$ day (World Cancer Research Fund \& American Institute for Cancer Research, 2007). Per gram of meat eaten, cured meat appears to be ten times more efficient to promote cancer than fresh red meat in Norat's study, and twice more in Larsson's.

- Consumption of "white meat", mostly poultry, is not associated with cancer risk $(\mathrm{RR}=1.01$; 95\%CI 0.90-1.13), and a high intake of fish brings a significant protection $(\mathrm{RR}=0.85$; 95\%CI 0.75-0.98) (highest vs. lowest category).

- The method of meat cooking and the doneness, and the human subjects' genetic polymorphism were not taken in account in the above reported studies, although many epidemiological studies address these questions. However, carcinogen chemicals are produced in meat when it is heated above $100^{\circ} \mathrm{C}$ or when it is cooked on an open flame (e.g., barbecue, see below). These carcinogens can be metabolized slowly in someone and fast in another one. The difference is due to genetic variations in p450 and $\mathrm{N}$-acetyltransferase, key detoxifying enzymes that help to eliminate carcinogens (LeMarchand, Hankin, \& al., 2002). The RR values given above thus represent the mean effect of meat, whatever the cooking, on the whole population, whatever the phenotype.

\section{4- Consequences and reliability of meta- analyses conclusions}

The risk fraction attributable to current levels of red meat intake in various countries was computed by Norat, under the hypothesis that there is a causal link between meat and cancer. The calculation suggests for instance that $25 \%$ of colorectal cancers are attributable to the average of $168 \mathrm{~g}$ of red meat that people are eating daily in Argentina. According to Norat's estimation, the excess risk would almost be zero when people eat less than $70 \mathrm{~g}$ red meat per week. Elio Riboli provided a recent estimate of the preventability of colorectal cancer (World Cancer Research Fund, 2010). According to his calculation, if USA citizen were eating red meat and processed meat less than once a week, colorectal cancer risk would be decreased by 5 and $12 \%$ respectively (World Cancer Research
Fund \& American Institute for Cancer Research, 2009). WCRF and AICR recommendations are to limit fresh red meat intake to less than 500 $\mathrm{g} /$ week in meat eaters, and to avoid processed meat ( $0 \mathrm{~g}$ per week). However, the choice of these thresholds is not clearly substantiated in the report (World Cancer Research Fund \& American Institute for Cancer Research, 2007).

In conclusion, these meta-analyses consistently show that red meat and processed meat consumption is significantly associated with a moderate increase in colorectal cancer risk (a relative risk lower than two is considered as "moderate"). Large prospective studies published after 2006 clearly confirmed these conclusions, notably the 500,000 subjects AARP cohort (A. J. Cross, et al., 2010; A. J. Cross, et al., 2007). The excess risk associated with red or processed meat intake was significant in both studies, and the hazard ratios (HR) values were 1.16-1.20 and 1.24 respectively, for the fifth quintile of meat intake compared with the first quintile. It is not surprising that most studies published before 2006 did not show a significant risk, because a small size study cannot show significance when the RR is close to one: these "negative" studies thus do not contradict the general pattern. Meat intake is not the only lifestyle factor that modulates colorectal cancer. According to the WCRF report, the following factors convincingly or probably decrease risk of colorectal cancer: physical activity, foods containing dietary fiber, garlic, milk and calcium; the following factors convincingly or probably increase risk: red and processed meat, alcoholic drinks, body and abdominal fatness, and adult attained height (World Cancer Research Fund \& American Institute for Cancer Research, 2007). Cigarette smoking also increases the risk, but was beyond the WCRF report scope. Table 1 shows that the magnitude of red meat effect on colorectal cancer is similar to that of other factors (fatness, alcohol, and smoking).

In addition, few review articles provide criticisms on the above cited studies, attempting to show that the link between meat and cancer is insignificant, but they failed to convince the 
author of the present review (Alexander \& Cushing, 2010; McAfee, et al., 2010; Truswell, 2002). To quote Demeyer et al.: "Although criticisms of the inaccurate definition of processed meats and the insufficient accounting for the large variability in composition of meat products have been expressed, it is clear that this problem urges proper action by the meat and nutrition research community and the meat industry" (Demeyer, et al., 2008).

Cohort studies are observations: they cannot fully avoid confounding factors. Thus a metaanalysis of cohort studies cannot demonstrate that a food is the cause of a cancer. Only a direct experiment can prove that a cause produces an effect. Indeed, many experimental studies have been done on meat-fed rodents. Do they support the meat-cancer link, and can they explain it? We will briefly review below the mechanistic hypotheses and the animal studies on the meat and cancer link.

\section{Meat and colorectal cancer: Mechanistic Hypotheses}

Several mechanistic hypotheses could explain how red meat and processed meat can increase colorectal cancer risk. Pro-cancer factors in red meat might be excess fat, excess protein, excess iron, or heat-induced mutagens. These factors may also act in processed meat, plus salt and nitrite added during the curing process. Other mechanisms might also play a role, but have not yet been investigated thoroughly. Dietary fat increases bile acids secretion inside the gut, and they act as aggressive surfactants for the mucosa thus increasing cell loss and proliferation (Bruce, 1987). In addition, fatty diets favor obesity which in turn increases insulin resistance and associated changes in blood values (high glucose, free fatty acids, insulin and IGF1): these circulating factors increase proliferation and decrease apoptosis $(=$ cell suicide $)$ of precancerous cells, thus promoting tumor growth (Calle \& Kaaks, 2004). Excess protein is fermented in the large bowel yielding amines, phenols and $\mathrm{H}_{2} \mathrm{~S}$ that are toxic to the mucosa (Visek \& Clinton, 1991). Iron induces production of genotoxic free radicals in the colonic stream (Nelson, 2001) and endogenous $\mathrm{N}$-nitrosated compounds such as carcinogenic $\mathrm{N}$ nitrosamines (S. A. Bingham, et al., 1996). Last, cooking meat at a high temperature or on an open flame (e.g., grilling, frying or barbecuing) produces heterocyclic amines and polycyclic aromatic hydrocarbons, which are potent carcinogens (Sugimura, Wakabayashi, Nakagama, \& Nagao, 2004).

However none of those hypotheses seems able, as such, to explain the link between meat intake and cancer risk. For instance, intervention studies in human volunteers do not show any change in intestinal tumor incidence with low-fat diet, suggesting fat is not a major promoter (Beresford, et al., 2006). In addition, a recent meta-analysis gathering 1.5 million subjects shows that animal fat intake is not a risk factor for cancer (Alexander, Cushing, Lowe, Sceurman, \& Roberts, 2009). The fermentation products from dietary proteins do not promote colon carcinogenesis in rodents (Corpet, et al., 1995). In several studies, inorganic iron failed to promote colorectal carcinogenesis, but Ilsley et al. showed in mice that a diet overloaded with ferric (FeIII) citrate increased tumor size, without promoting preneoplastic lesions or the incidence of colon adenoma. The oxidative status of iron in the gut was not determined (Ilsley, et al., 2004). Carcinogenic doses of heterocyclic amines in rodents are more than 10000 times higher than levels found in human foods. Grilled and fried chicken contain much more heterocyclic amines than beef meat, but intake of poultry is not related to cancer risk (Heddle, Knize, Dawod, \& Zhang, 2001). It is however likely that all heterocyclic amines have not the same carcinogenic potency (beef ones seems more potent in humans than chicken ones), and that some individuals are more susceptible, due to genetic polymorphisms or intestinal microbiote. For instance, smokers with fast $\mathrm{N}$-acetyltransferase are more susceptible to cancer promotion by well done meat than those with a slow $\mathrm{N}$-acetyltransferase (LeMarchand, et al., 2002). Also the intestinal microbiote adapts to meat intake and heterocyclic amines might be more genotoxic in individuals that consume high amounts of meats (Kassie, et al., 2004). 
However, most studies of meat and phenotypes interactions are deceiving and the general picture is not convincing. Last, cereals, not meat, are the major source of polycyclic aromatic hydrocarbons (Phillips, 1999). It is however probable that heat-induced mutagens found on the surface of well-done beef meat can cause colon cancer in people with genetic predisposition. Salt (sodium chloride) and sodium nitrite do not promote colon carcinogenesis in rodents, and salt intake is not associated with CRC risk (but with gastric cancer risk, see below). However, sodium chloride could enhance fat oxidation in meat, increasing the TBARs level and slightly reducing the pool of antioxidant enzymes (Gheisari \& Motamedi, 2010). Since none of the above cited hypotheses seem satisfactory, we will review here the animal studies on meat and cancer, and report recent studies from our laboratory, and related studies in Omaha, Nebraska and in Cambridge, UK.

\section{Meat and colorectal cancer: Cancer studies in rodents}

Before 2004 twelve rodent studies investigated the effect of a meat-based diet, but none could show the promoting effect of meat on tumorigenesis in rats or mice. In contrast, and very surprisingly, meat diets appear to protect rats and mice against chemically induced carcinogenesis. Below is given a brief summary of those twelve studies that have been reviewed elsewhere (Parnaud \& Corpet, 1997):

- Diets that are very high in fat or in protein usually promote carcinogenesis in rats, whatever the fat or protein source, and meat is not "worse" than soy or casein (Reddy, Narisawa, \& Weisburger, 1976). Rats given a high-beef meat diet $(50 \%$, low fat) have the same number of tumors than casein-fed rats (Lai, Dunn, Miller, \& Pence, 1997). Raw and grilled beef meat diet (20\%) do not change tumor incidence in rats compared with a soy-protein diet (Clinton SK, 1979). Kangaroo meat diet (23\%) results in the same tumor incidence than casein or soy protein diets in rats (McIntosh, Regester, Leleu, Royle, \& Smithers, 1995).
- Surprisingly, a diet with $60 \%$ cooked beef meat significantly protects rats against carcinogenesis compared with a casein control diet (Pence, et al., 1995). Compared with a casein-based diet, well done cooked meat (60\% of diet, with $35 \%$ moisture and a high load of heterocyclic amines) reduces colon cancer risk in rats, in a high-fat context. By contrast in a low-fat context, welldone meat increases cancer risk (Pence, Landers, Dunn, Shen, \& Miller, 1998). Mice given a highbeef meat diet $(46 \%)$ have fewer tumors than casein fed mice (Nutter, Gridley, Kettering, Goude, \& Slater, 1983). Grilled beef meat or bacon diets (30 and 60\%), do not increase the number or the size of carcinogen-induced aberrant crypt foci (ACF, preneoplastic lesions) in rats, but bacon diet reduces the ACF size (Parnaud, Peiffer, Tache, \& Corpet, 1998). Min mice are mutated on the Apc gene and develop many intestinal tumors. Female Min mice given beef meat have less tumors than control Min mice given a no-meat diet (Kettunen, Kettunen, \& Rautonen, 2003).

- Three studies seem to contrast with the above cited ones, but a careful look at the methods reveals meat was not responsible for the tumor promotion: Rats given a humanized diet containing $25 \%$ beef meat have more colon cancer than rats on a rodent chow. However, the rodent chow contained much more fibers and less fat than the humanized diet (Alink, Kuiper, Hollanders, \& Koeman, 1993). A small increase in jejunum polyp number was reported in Min mice given a $24 \%$ beef meat diet, but the effect was not significant, and the meat diet contained five times more fat than the control diet (Mutanen, Pajari, \& Oikarinen, 2000). Last, compared with a whey protein diet, a kangaroo meat diet increases the number of ACF in rats, but whey proteins have known chemopreventive properties and may not be a "neutral" control diet (Belobrajdic, Mcintosh, \& Owens, 2003).

The discrepancy between epidemiology and animal studies is a paradox: Epidemiology suggests red meat promotes cancer while meat diets show no effect or protection on rodents. Could this discrepancy be explained, and resolved? The next paragraph reports the most likely hypothesis that can, according to the 
author, explain the effect of meat on cancer and resolve the above-cited paradox.

\section{The heme iron hypothesis: fat peroxidation and $\mathrm{N}$-nitroso pathways}

We reasoned that red meat would contain a toxic compound absent in white meat. This toxic compound would be either inactive in rodents or inhibited by rodent diet. Based on works of Van der Meer (Sesink, Termont, Kleibeuker, \& Vandermeer, 1999), and of Sawa (Sawa, et al., 1998) we thus speculated that heme iron would be a major player in cancer promotion, explaining why red meat, but not white meat, is associated with cancer risk. This hypothesis is supported by a meta-analysis of epidemiological studies that shows a suggestive association between dietary heme and risk of colon cancer (Bastide, Pierre, \& Corpet, 2011). We also speculated that calcium would bind heme iron and suppress its toxicity. This would explain why no animal study published before 2004 and using the high-calcium standard AIN76 diet could show red meat promotion (AIN, 1977).

Our team brought the first demonstration that beef meat added to a low-calcium diet promotes early stages of colon carcinogenesis in chemically-initiated rats. We also demonstrated a dose-response relationship between heme iron and promotion: Tumor number was higher in black pudding-fed (blood sausage) rats than in beef meat fed rats. Tumor promotion was identical in beef meat-fed rats and in rats given a heme-equivalent diet with hemoglobin, but not in rats given the same level of inorganic iron (ferric citrate). In contrast, chicken breast meat did not promote carcinogenesis as it contains little heme iron (Pierre, Freeman, Tache, Van der Meer, \& Corpet, 2004). Our hypothesis on heme iron, calcium and cancer was thus demonstrated experimentally. We then wanted to explore the mechanism(s) by which heme iron can promote cancer, and we now think that two independent pathways may link heme and cancer: The fat peroxidation pathway and the N-nitroso pathway that are presented on Fig.1 (reprinted from (Bastide, et al., 2011)).
- We think that the fat peroxidation pathway mainly explains tumor promotion by fresh red meat. Our studies consistently show that carcinogenesis promotion by dietary heme iron is associated with the urinary excretion of a fat peroxidation biomarker, called 1,4dihydroxynonane mercapturic acid (DHN-MA) (F. Pierre, et al., 2004). DHN-MA excretion also increases in the urine of volunteers that are given black pudding, a heme iron loaded blood sausage (Pierre, et al., 2006). In feces also, high-heme iron diets consistently increase the level of TBARs, an overall measure of aldehyde molecules due to fat oxidation. The oxidation of polyunsaturated fatty acids by hemoglobin leads to peroxyl radicals formation in refined vegetable oils (Sawa, et al., 1998). The main aldehyde molecules are malondialdehyde (MDA) and 4-hydroxynonenal (4-HNE) (Marnett, 2000). MDA is toxic and binds DNA, forming mutagenic adducts. 4-HNE induces apoptosis and kills normal cells, but not precancerous cells that are mutated on the Apc gene, because they resist to apoptosis induction (Pierre, et al., 2007). The selective cytotoxicity of 4-HNE explains tumor promotion by a selection process, like the selection of resistant bacteria by an antibiotic (Corpet, Tache, \& Peiffer, 1997).

- We think the $\mathbf{N}$-nitroso pathway mainly explains that nitrite-cured meat favors cancer. Feces from rats and mice fed bacon- or hot-dogbased diets contains 5-20 times more N-nitrosocompounds than feces from control rodents fed a casein-based diet (Mirvish, et al., 2003; Parnaud, Pignatelli, Peiffer, Tache, \& Corpet, 2000). Our studies show that cured-meat promotion of carcinogenesis in rats is associated with a high level of fecal apparent total nitroso-compounds (Santarelli, et al., 2010). This pathway is not limited to cured-meat, since a diet high in fresh red meat $(600 \mathrm{~g} / \mathrm{d}$ compared with $60 \mathrm{~g} / \mathrm{d})$ induces a 3-fold increase in fecal nitroso-compounds (Bingham, et al., 1996). This endogenous production of nitroso-compounds is specifically caused by the intake of heme iron in fresh red beef meat (Cross, Pollock, \& Bingham, 2003). Pork meat contains less heme iron than beef meat, but nitrite favors the endogenous production of nitroso-compounds in volunteers 
given cured-meat (Joosen, et al., 2009). The nature of the nitroso-compounds formed in the gut is not fully known (Zhou, et al., 2006). Most assays indeed gather Fe-nitrosyl heme, Snitroso-thiols with $\mathrm{N}$-nitroso-compounds, and the resulting value is called ATNC for "apparent total nitroso-compounds" (Kuhnle, et al., 2007). The main part of ATNC in volunteers given red meat is made of Fe-nitrosyl-heme, but those given cured-meat had 2-3 times more "true" $\mathrm{N}$ nitroso-compounds than fresh meat eaters (Joosen, et al., 2009). Several N-nitrosocompounds are known carcinogen in rodents, and they can alkylate DNA. In volunteers, the red meat associated endogenous NOC formation has been correlated with the formation of the Nnitroso-specific DNA adduct, O6carboxymethylguanine (O6-CMG) in vivo (Lewin, et al., 2006).

- A third pathway may also explain the effect of red meat: a direct effect of heme on colonic cells. This mechanism has received limited support from studies on cancer cells in vitro. They show that hemin induces DNA damage in human cells of colonic origin (Glei, et al., 2006), via hydrogen peroxide produced by hemeoxygenase, which can be inhibited in vitro by Zn-protoporphyrin (Ishikawa, Tamaki, Ohata, Arihara, \& Itoh, 2010).

\section{Making safer meat}

We then reasoned that knowing the toxicity of heme iron and its pathways to toxicity, we may find ways to suppress the toxicity. As reported above, we knew from van der Meer's publications that heme iron is trapped by calcium phosphate and by chlorophyll (Sesink, Termont, Kleibeuker, \& VanDerMeer, 2001). Van der Meer and colleagues speculated that heme, a planar hydrophobic molecule with polar side chains (like unconjugated bilirubin and bile salts) would bind with calcium ions incorporated in a crystal, by alignment between anionic groups and calcium (Sesink, et al., 2001; van der Veere, et al., 1995). They also speculated that chlorophyll and heme that both are planar hydrophobic porphyrins can stack together in the hydrophobic phase of the luminal contents (de Vogel, Jonker-Termont, Katan, \& van der Meer, 2005). We thus designed an experiment showing that promotion of carcinogenesis in the colon of rats by hemin, a chlorinated chemical form of free heme iron, is fully suppressed by dietary calcium (Pierre, Tache, Petit, Van der Meer, \& Corpet, 2003). We also showed that calcium carbonate suppresses promotion by beef meat (Pierre, Santarelli, Tache, Gueraud, \& Corpet, 2008) and is more efficient than calcium phosphate, without side-effects (Allam, et al., 2011). However, although it is non-toxic and shows potent and consistent protection, calcium has two drawbacks: (i) it modifies meat Callow's structure and makes it hard and dry; and (ii) it binds heme iron and thus reduces its absorption. In Europe, iron deficiency is one of the main nutritional deficiency disorders affecting large fractions of the population, particularly menstruating and pregnant women. We thus looked for other way to prevent meat promotion without blocking heme iron, by suppressing the fat peroxidation pathway or the $\mathrm{N}$-nitroso pathway.

Peroxidation and nitrosation may be reduced by adding antioxidant or antinitrosant additives to meat. In addition, peroxidation is prevented by removing oxygen, and nitrosation is prevented by removing nitrite from meat or from the gastrointestinal tract. In a study on chemicallyinitiated rats, cured pork meat without sodium nitrite, or packaged to prevent oxidation, does not promote carcinogenesis, in contrast to nitritecured meat exposed to open air for five days in a refrigerator (Santarelli, et al., 2010). Freezedried cooked ham (with nitrite) purchased in a shop also promotes carcinogenesis in rats (Pierre, et al., 2010), because freeze-drying boosts fat peroxidation (Gasc, et al., 2007). Adding antioxidant butylated hydroxyanisole with rutin, or oxidation-resistant olive oil, to a hemin-loaded diet fully prevents the promoting effect of hemin, a proxi for meat heme iron (F. Pierre, et al., 2003). In rats, cured meat increased the number of precancerous lesions in the gut, and fecal lipoperoxidation (TBARs). When added as a food additive to the curing solution, $\alpha$-tocopherol (vitamin E) fully normalized the 
preneoplastic lesions per colon, and reduced fecal TBARS in cured meat-fed rats. Similarly, TBARS significantly increased in stools of volunteers given cured meat compared to the meat-free period. Calcium supplements or $\alpha$ tocopherol addition fully normalized fecal TBARS in volunteers given cured meat (Santarelli, manuscript in preparation).

We thus have demonstrated in animal studies that red meat and processed meat can promote colon carcinogenesis. As reported above, we provide several ways to prevent this toxic effect by changing the diet, the process, or additives:

- Diet change: Calcium carbonate supplements bind heme iron and suppress carcinogenesis promotion in rats, and associated peroxidation biomarkers in rats and volunteers. We suggest that dairy products would produce the same effect. Other way to change diet is to reduce meat intake, following WCRF recommendations.

- Process changes: Preventing the oxidation of fat during meat processing storage with an anaerobic packaging reduces ham-induced promotion. Also, omission of nitrite in curing solution suppressed ham-induced promotion. However, it will not be easy to get rid of nitrite.

- Additives: $\alpha$-tocopherol added to the curingsolution suppresses cured-meat promotion in rats, and associated biomarkers in human volunteers (unpublished results). Our team is still working on this issue, looking for natural antioxidant and/or anti-nitrosant agents that might be added to meat, notably plant polyphenols. Twelve molecules or extracts from fruits, leaves or rhizome have already been tested in short-term in vivo studies with biochemical endpoints. We are currently testing the most promising chemopreventive agents in a long term carcinogenesis study.

\section{Meat intake and other cancers}

Meat consumption appears to increase modestly the risk of colorectal cancer, and thus to be a minor cause of cancer in Western countries. Could meat intake increase also the risk of other cancers, particularly the frequent breast and prostate cancers? Several cohort studies show that cured meat particularly boosts the risk of gastric cancer, likely because of salt and nitrite, but this cancer is rare in affluent countries. For instance in the EPIC study, total meat intake is associated with a RR of stomach cancer of 3.5 (95\%CI 2-6) (Gonzalez, et al., 2006). However, the WCRF-AICR report concluded the risk was not convincing nor probable but limitedsuggestive. The link seems much weaker with breast and prostate cancers, and did show up neither in a breast cancer meta-analysis (Missmer, et al., 2002), nor in the very large European EPIC study of half a million persons. In an American study of similar size, elevated risks (ranging from $+20 \%$ to $+60 \%$ ) were evident for oesophageal, colorectal, liver, and lung cancer (but neither breast nor prostate) (A. J. Cross, et al., 2007).

\section{Discussion and conclusion}

The above reported observation studies clearly show that consumers of processed meat (mainly cured pork) and of red meat (mainly beef) have a modest increase in their risk to develop a colorectal cancer. Our experimental studies in rats suggest the effect is not due to confounding factors, but comes from true toxic factor(s) in red and processed meat. From an individual perspective, $+25 \%$ risk is a rather small increase. Let us assume that one person out of 20 have a colorectal cancer, this figure would increase from 1.0 to 1.2 out of 20 in the most "carnivorous" fraction of the population. In contrast, the risk increase seems large from a public health perspective. Let us assume that one hundred people in France are told each day they have colorectal cancer. The excess risk associated with a daily steak, $+25 \%$, would now translate to an extra 25 people each day with cancer, which is not acceptable!

One may think that the global risk had been estimated mostly from American data and would not apply to other parts of the world, particularly Europe. But Larsson's meta-analysis specifically addressed this question, and her data show that the risk increase per gram of meat consumption is not different in Europe and in the USA (Larsson \& Wolk, 2006). In addition, results from meat intake surveys do not show large 
differences between meat intake in Europe and North-America. For instance, the French INCA2 survey shows that red meat and processed meat intake are $370 \mathrm{~g}$ and $270 \mathrm{~g}$ per week respectively in France (Volatier \& Dufour, 2006). Distribution data show that a quarter of the French adult population (39\% men and 13\% women) eats more red meat than the recommended $500 \mathrm{~g}$, and a quarter eats more than $50 \mathrm{~g} / \mathrm{d}$ processed meat (we do not know how much these two populations overlap). Thus, at least in France, the cancer burden due to fresh meat consumption should be roughly equivalent to the burden due to processed meat.

Our experimental studies in rats provide direct evidence that red meat and processed meat can increase colon carcinogenesis. They also strongly support the hypothesis that heme iron is the major cause of cancer promotion by red meat. Based on works by other researchers, our results add some evidence to two pathways linking dietary heme iron and cancer promotion. Lastly, we are suggesting several ways to prevent the toxic effect of meat, either by increasing the calcium load of the meal, by changing the meat processing, or by choosing new additives. Full demonstration of mechanisms and of chemopreventive substances has not yet been given, but we expect that these studies will lead to a reduction of the risk of colorectal cancer without losing the nutritional benefit and the pleasure of eating meat.

\section{Acknowledgments}

Many thanks are due to Fabrice Pierre for his help in writing this review, to Conner Middelmann-Whitney for editing the title, to Nadia Bastide for composing the figure, and to the four anonymous Reviewers who suggested many improvements. D.E. Corpet's team researches are supported by French INRA, DGER, and ANR projects HemeCancer and SecuriViande.

Table 1: Summary estimates of relative risk on colorectal cancer, from cohort studies meta-analysis (World Cancer Research Fund \& American Institute for Cancer Research, 2007).

\begin{tabular}{|c|c|c|c|c|c|}
\hline Factor & $\begin{array}{l}\text { Evidence } \\
\text { strength }^{\text {a }}\end{array}$ & $\begin{array}{l}\text { Percent } \\
\text { change }\end{array}$ & $\begin{array}{c}\text { Summary } \\
\text { RR }^{c}\end{array}$ & $\underset{d}{\text { Signif. }}$ & per \\
\hline Abdominal fatness ${ }^{\mathrm{e}}$ & $\mathrm{C}$ & 30 & 1.30 & * & $0.1 \mathrm{~W}$-to-H \\
\hline Red meat & $\mathrm{C}$ & 29 & 1.29 & * & $100 \mathrm{~g} / \mathrm{d}$ \\
\hline Garlic & $\mathrm{P}$ & 27 & 0.73 & $*$ & high vs. low \\
\hline Alcohol & $\mathrm{C}$ & 27 & 1.27 & $*$ & $30 \mathrm{~g} / \mathrm{d}$ \\
\hline Smoking $^{c}$ & $\mathrm{C}$ & 25 & 1.25 & $*$ & ever vs. never \\
\hline Processed meat & $\mathrm{C}$ & 21 & 1.21 & $*$ & $50 \mathrm{~g} / \mathrm{d}$ \\
\hline Body fatness ${ }^{e}$ & $\mathrm{C}$ & 15 & 1.15 & $*$ & $5 \mathrm{~kg} / \mathrm{m}^{2}$ \\
\hline Dietary fiber & $\mathrm{P}$ & 10 & 0.90 & $*$ & $10 \mathrm{~g} / \mathrm{d}$ \\
\hline Adult attained height & $\mathrm{C}$ & 9 & 1.09 & $*$ & $5 \mathrm{~cm}$ \\
\hline Milk & $\mathrm{P}$ & 6 & 0.94 & NS & serving/d \\
\hline Calcium & $\mathrm{P}$ & 2 & 0.98 & MS & $200 \mathrm{mg} / \mathrm{d}$ \\
\hline
\end{tabular}

a- $\mathrm{C}$, convincing; $\mathrm{P}$, probable. Factors with limited/suggestive evidence are not reported in Table 1.

b- Percent change $=100$ times the absolute value of $(\mathrm{RR}-1)$

c- Summary estimates of Relative Risk were extracted from the WCRF-AICR 2007 report, except value for smoking, not reported in the report, and extracted from a recent meta-analysis (Botteri, et al., 2008).

d- Significance: $*$ the $95 \%$ confidence interval excludes 1.00 ; NS, non significant; MS, marginally significant (1.00 is the upper value of the confidence interval)

e- Abdominal fatness measured by the Waist-to-Hip ratio, and body fatness by the Body Mass Index. 
Figure 1

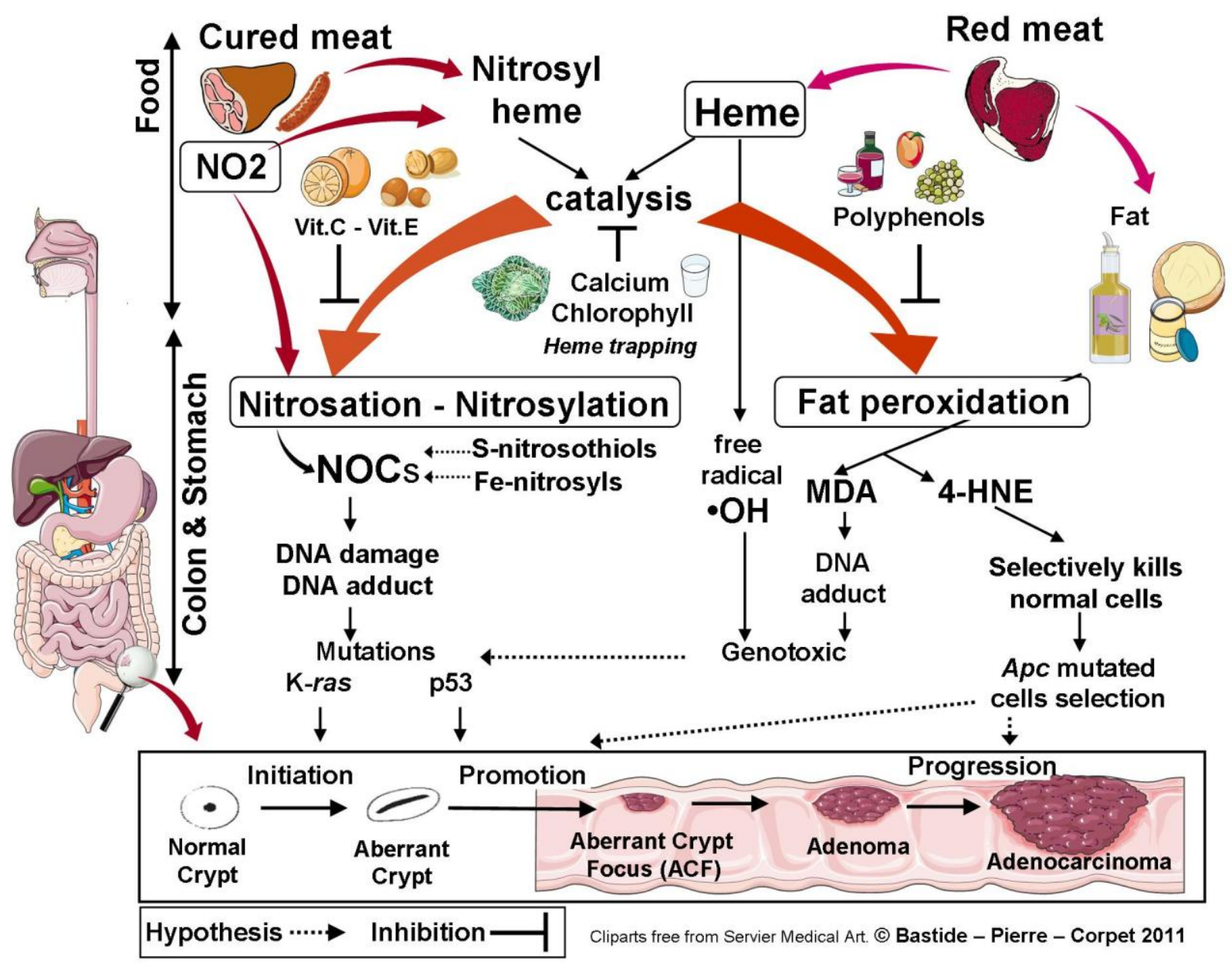

Fig. 1. Catalytic effect of heme iron on fat peroxidation and N-nitrosation, and their inhibition by dietary means. Consequences for the development of colorectal cancer. Reprinted with modifications from Cancer Prevention Research (Bastide et al., 2011).

Heme iron catalyzes nitrosation and fat peroxidation. End products are $\mathrm{N}$-nitroso compounds (NOCs), malondialdehyde (MDA) and 4-hydroxy-nonenal (4-HNE). These pathways explain, at least in part, the promoting effect of red and cured meat on colorectal cancer. The catalytic effects of heme iron can be inhibited by trapping heme with calcium carbonate or chlorophyll. The endogenous formation of NOCs is inhibited by vitamin $\mathrm{C}$ and E. Ongoing studies suggest that specific polyphenols can inhibit fat peroxidation and/or nitrosation. 


\section{References}

Alexander, D. D., \& Cushing, C. A. (2010). Red meat and colorectal cancer: a critical summary of prospective epidemiologic studies. Obes Rev, DOI: 10.1111/j.1467-789X.2010.00785.x.

Alexander, D. D., Cushing, C. A., Lowe, K. A., Sceurman, B., \& Roberts, M. A. (2009). Meta-analysis of animal fat or animal protein intake and colorectal cancer. Am J Clin Nutr, 89(5), 1402-1409.

Alink, G. M., Kuiper, H. A., Hollanders, V. M. H., \& Koeman, J. H. (1993). Effect of heat processing and of vegetables and fruit in human diets on 1,2dimethylhydrazine-induced colon carcinogenesis in rats. Carcinogenesis, 14(3), 519-524.

Allam, O., Bahuaud, D., Tache, S., Naud, N., Corpet, D. E., \& Pierre, F. H. (2011). Calcium carbonate suppresses haem toxicity markers without calcium phosphate side effects on colon carcinogenesis. Br J Nutr, 105(3), 384-392.

American, I. o. N. (1977). Report of the American Institute of Nutrition Ad Hoc Committee on standards for nutritional studies. J Nutr, 107, $1340-1348$.

Bastide, N. M., Pierre, F. H., \& Corpet, D. E. (2011). Heme Iron from Meat and Risk of Colorectal Cancer: A Meta-analysis and a Review of the Mechanisms Involved. Cancer Prev Res (Phila), 4(2), 177-184.

Belobrajdic, D. P., Mcintosh, G. H., \& Owens, J. A. (2003). Whey proteins protect more than red meat against azoxymethane induced ACF in wistar rats. Cancer Letters, 198(1), 43-51.

Beresford, S. A., Johnson, K. C., Ritenbaugh, C., Lasser, N. L., Snetselaar, L. G., Black, H. R., et al. (2006). Low-fat dietary pattern and risk of colorectal cancer: the Women's Health Initiative Randomized Controlled Dietary Modification Trial. JAMA, 295(6), 643-654.

Bingham, S., \& Riboli, E. (2004). Diet and cancer - The European prospective investigation into cancer and nutrition. Nature Reviews Cancer, 4(3), 206-215.

Bingham, S. A., Pignatelli, B., Pollock, J. R. A., Ellul, A., Malaveille, C., Gross, G., Runswick, S., Cummings, J. H., \& Oneill, I. K. (1996). Does increased endogenous formation of $\mathrm{N}$-nitroso compounds in the human colon explain the association between red meat and colon cancer? Carcinogenesis, $17(3), 515-523$.

Botteri, E., Iodice, S., Bagnardi, V., Raimondi, S., Lowenfels, A. B., \& Maisonneuve, P. (2008). Smoking and colorectal cancer: a meta-analysis. JAMA, $300(23), 2765-2778$.

Bruce, W. R. (1987). Recent hypotheses for the origin of colon cancer. Cancer Res, 47, 4237-4242.

Calle, E. E., \& Kaaks, R. (2004). Overweight, obesity and cancer: epidemiological evidence and proposed mechanisms. Nat Rev Cancer, 4(8), $579-591$.

Clinton SK, D. R., Anderson DB, Truex CR, Imrey PB, Visek WJ. (1979). 1,2-dimethylhydrazine induced intestinal cancer in rats fed beef or soybean protein. Nutrition reports international, 20, 335-342.

Corpet, D. E., Tache, S., \& Peiffer, G. (1997). Colon tumor promotion: is it a selection process? effects of cholate, phytate, and food restriction in rats on proliferation and apoptosis in normal and aberrant crypts. Cancer Letters, 114(1-2), 135-138.

Corpet, D. E., Yin, Y., Zhang, X. M., Remesy, C., Stamp, D., Medline, A., Thompson, L., Bruce, W. R., \& Archer, M. C. (1995). Colonic protein fermentation and promotion of colon carcinogenesis by thermolyzed casein. Nutrition and Cancer - an International Journal, 23(3), 271-281.

Cross, A. J., Ferrucci, L. M., Risch, A., Graubard, B. I., Ward, M. H., Park, Y., Hollenbeck, A. R., Schatzkin, A., \& Sinha, R. (2010). A large prospective study of meat consumption and colorectal cancer risk: an investigation of potential mechanisms underlying this association. Cancer Res, 70(6), 2406-2414.

Cross, A. J., Leitzmann, M. F., Gail, M. H., Hollenbeck, A. R., Schatzkin, A., \& Sinha, R. (2007). A prospective study of red and processed meat intake in relation to cancer risk. PLoS Med, 4(12), e325.

Cross, A. J., Pollock, J. R. A., \& Bingham, S. A. (2003). Haem, not protein or inorganic iron, is responsible for endogenous intestinal n-nitrosation arising from red meat. Cancer Research, 63(10), 2358-2360.

de Vogel, J., Jonker-Termont, D. S., Katan, M. B., \& van der Meer, R. (2005). Natural chlorophyll but not chlorophyllin prevents heme-induced cytotoxic and hyperproliferative effects in rat colon. J Nutr, 135(8), 1995-2000.

Demeyer, D., Honikel, K., \& De Smet, S. (2008). The World Cancer Research Fund report 2007: A challenge for the meat processing industry Meat Science, 80(4), 953-959

Gasc, N., Tache, S., Rathahao, E., Bertrand-Michel, J., Roques, V., \& Gueraud, F. (2007). 4-hydroxynonenal in foodstuffs: heme concentration, fatty acid composition and freeze-drying are determining factors. Redox Rep, 12(1), 40-44.

Gheisari, H. R., \& Motamedi, H. (2010). Chloride salt type/ionic strength and refrigeration effects on antioxidant enzymes and lipid oxidation in cattle, camel and chicken meat. Meat Sci, 86(2), 377-383.

Glei, M., Klenow, S., Sauer, J., Wegewitz, U., Richter, K., \& Pool-Zobel, B. L. (2006). Hemoglobin and hemin induce DNA damage in human colon tumor cells HT29 clone 19A and in primary human colonocytes. Mutat Res, 594(1-2), 162-171.

Gonzalez, C. A., Jakszyn, P., Pera, G., Agudo, A., Bingham, S., et al. (2006). Meat intake and risk of stomach and esophageal adenocarcinoma within the European Prospective Investigation Into Cancer and Nutrition (EPIC). J Natl Cancer Inst, 98(5), 345-354.

Heddle, J. A., Knize, M. G., Dawod, D., \& Zhang, X. B. (2001). A test of the mutagenicity of cooked meats in vivo. Mutagenesis, $16(2), 103-107$.

Ilsley, J. N. M., Belinsky, G. S., Guda, K., Zhang, Q., Huang, X., Blumberg, J. B., Milbury, P. E., Roberts, L. J., Stevens, R. G., \& Rosenberg, D. W. (2004). Dietary iron promotes azoxymethane-induced colon tumors in mice. Nutrition and Cancer-an International Journal, 49(2), $162-169$.

INCa, I. N. d. C.-F., \& NACRe, R. N. A. C. R.-. (2009). Nutrition et Prévention des Cancers: des connaissances scientifiques aux recommandations. Les synthèses du Programme National Nutition Santé, PNNS, France, 7, 1-50.

Ishikawa, S., Tamaki, S., Ohata, M., Arihara, K., \& Itoh, M. (2010). Heme induces DNA damage and hyperproliferation of colonic epithelial cells via hydrogen peroxide produced by heme oxygenase: a possible mechanism of heme-induced colon cancer. Mol Nutr Food Res, 54(8), $1182-1191$.

Joosen, A. M., Kuhnle, G. G., Aspinall, S. M., Barrow, T. M., Lecommandeur, E., Azqueta, A., Collins, A. R., \& Bingham, S. A. (2009). Effect of processed and red meat on endogenous nitrosation and DNA damage. Carcinogenesis, 30(8), 1402-1407.

Kassie, F., Lhoste, E. F., Bruneau, A., Zsivkovits, M., Ferk, F., Uhl, M., Zidek, T., \& Knasmuller, S. (2004). Effect of intestinal microfloras from vegetarians and meat eaters on the genotoxicity of 2-amino-3-methylimidazo 4,5-f quinoline, a carcinogenic heterocyclic amine. Journal of Chromatography B-Analytical Technologies in the Biomedical and Life Sciences, 802(1), 211-215.

Kettunen, H. L., Kettunen, A. S. L., \& Rautonen, N. E. (2003). Intestinal immune responses in wild-type and apc(min/+) mouse, a model for colon cancer. Cancer Research, 63(16), 5136-5142.

Kuhnle, G. G., Story, G. W., Reda, T., Mani, A. R., Moore, K. P., Lunn, J. C., \& Bingham, S. A. (2007). Diet-induced endogenous formation of nitroso compounds in the GI tract. Free Radic Biol Med, 43(7), 1040-1047.

Lai, C., Dunn, D. M., Miller, M. F., \& Pence, B. C. (1997). Non-promoting effects of iron from beef in the rat colon carcinogenesis model. Cancer Letters, $112(1), 87-91$.

Larsson, S. C., \& Wolk, A. (2006). Meat consumption and risk of colorectal cancer: a meta-analysis of prospective studies. Int J Cancer, 119(11), 2657-2664.

LeMarchand, L., Hankin, J. H., \& al., e. (2002). Well-done red meat, metabolic phenotypes and colorectal cancer in Hawaii. Mutation Research, 506-507, 205-214.

Lewin, M. H., Bailey, N., Bandaletova, T., Bowman, R., Cross, A. J., Pollock, J., Shuker, D. E., \& Bingham, S. A. (2006). Red meat enhances the colonic formation of the DNA adduct O6-carboxymethyl guanine: implications for colorectal cancer risk. Cancer Res, 66(3), 1859-1865. 
Marnett, L. J. (2000). Oxyradicals and DNA damage. Carcinogenesis, 21(3), 361-370.

McAfee, A. J., McSorley, E. M., Cuskelly, G. J., Moss, B. W., Wallace, J. M., Bonham, M. P., \& Fearon, A. M. (2010). Red meat consumption: an overview of the risks and benefits. Meat Sci, 84(1), 1-13.

McIntosh, G. H., Regester, G. O., Leleu, R. K., Royle, P. J., \& Smithers, G. W. (1995). Dairy proteins protect against dimethylhydrazine-induced intestinal cancers in rats. Journal of Nutrition, 125(4), 809-816.

Mirvish, S. S., Haorah, J., Zhou, L., Hartman, M., Morris, C. R., \& Clapper, M. L. (2003). N-nitroso compounds in the gastrointestinal tract of rats and in the feces of mice with induced colitis or fed hot dogs or beef. Carcinogenesis, 24(3), 595-603.

Missmer, S. A., Smithwarner, S. A., Spiegelman, D., Yaun, S. S., Adami, H. O., et al. (2002). Meat and dairy food consumption and breast cancer: a pooled analysis of cohort studies. International Journal of Epidemiology, 31(1), 78-85.

Mutanen, M., Pajari, A. M., \& Oikarinen, S. I. (2000). Beef induces and rye bran prevents the formation of intestinal polyps in apc(min) mice: relation to betacatenin and PKC isozymes. Carcinogenesis, 21(6), 1167-1173.

Nelson, R. L. (2001). Iron and colorectal cancer risk: human studies. Nutrition Reviews, 59(5), 140-148.

Norat, T., Lukanova, A., Ferrari, P., \& Riboli, E. (2002). Meat consumption and colorectal cancer risk: dose-response meta-analysis of epidemiological studies. International Journal of Cancer, 98(2), 241-256.

Norat, T., \& Riboli, E. (2001). Meat consumption and colorectal cancer: a review of epidemiologic evidence. Nutrition Reviews, 59(2), 37-47.

Nutter, R. L., Gridley, D. S., Kettering, J. D., Goude, A. G., \& Slater, J. M. (1983). BALB/c mice fed milk or beef protein: differences in response to 1,2dimethylhydrazine carcinogenesis. J Natl Cancer Inst, 71(4), 867-874.

Parnaud, G., \& Corpet, D. E. (1997). Colorectal cancer: controversial role of meat consumption. Bulletin du Cancer, 84(9), 899-911.

Parnaud, G., Peiffer, G., Tache, S., \& Corpet, D. E. (1998). Effect of meat (beef, chicken, and bacon) on rat colon carcinogenesis. Nutrition and Cancer, 32(3), $165-173$.

Parnaud, G., Pignatelli, B., Peiffer, G., Tache, S., \& Corpet, D. E. (2000). Endogenous N-nitroso compounds, and their precursors, present in bacon, do not initiate or promote aberrant crypt foci in the colon of rats. Nutrition and Cancer, 38(1), 74-80.

Pence, B. C., Butler, M. J., Dunn, D. M., Miller, M. F., Zhao, C., \& Landers, M. (1995). Non-promoting effects of lean beef in the rat colon carcinogenesis model. Carcinogenesis, 16(5), 1157-1160.

Pence, B. C., Landers, M., Dunn, D. M., Shen, C. L., \& Miller, M. F. (1998). Feeding of a well-cooked beef diet containing a high heterocyclic amine content enhances colon and stomach carcinogenesis in 1,2-dimethylhydrazine-treated rats. Nutrition and Cancer, 30(3), 220-226.

Phillips, D. H. (1999). Polycyclic aromatic hydrocarbons in the diet. Mutat Res, 443(1-2), 139-147.

Pierre, F., Freeman, A., Tache, S., Van der Meer, R., \& Corpet, D. E. (2004). Beef meat and blood sausage promote the formation of azoxymethane-induced mucin-depleted foci and aberrant crypt foci in rat colons. Journal of Nutrition, 134(10), 2711-2716.

Pierre, F., Peiro, G., Tache, S., Cross, A. J., Bingham, S. A., Gasc, N., Gottardi, G., Corpet, D. E., \& Gueraud, F. (2006). New marker of colon cancer risk associated with heme intake: 1,4-dihydroxynonane mercapturic Acid. Cancer Epidemiol Biomarkers Prev, 15(11), 2274-2279.

Pierre, F., Santarelli, R., Tache, S., Gueraud, F., \& Corpet, D. E. (2008). Beef meat promotion of dimethylhydrazine-induced colorectal carcinogenesis biomarkers is suppressed by dietary calcium. Br J Nutr, 99(5), 1000-1006.

Pierre, F., Tache, S., Gueraud, F., Rerole, A. L., Jourdan, M. L., \& Petit, C. (2007). Apc mutation induces resistance of colonic cells to lipoperoxide-triggered apoptosis induced by faecal water from haem-fed rats. Carcinogenesis, 28(2), 321-327.

Pierre, F., Tache, S., Petit, C. R., Van der Meer, R., \& Corpet, D. E. (2003). Meat and cancer: haemoglobin and haemin in a low-calcium diet promote colorectal carcinogenesis at the aberrant crypt stage in rats. Carcinogenesis, 24(10), 1683-1690.

Pierre, F. H., Santarelli, R. L., Allam, O., Tache, S., Naud, N., Gueraud, F., \& Corpet, D. E. (2010). Freeze-dried ham promotes azoxymethane-induced mucindepleted foci and aberrant crypt foci in rat colon. Nutr Cancer, 62(5), 567-573.

Reddy, B. S., Narisawa, T., \& Weisburger, J. H. (1976). Effect of a diet with high levels of protein and fat on colon carcinogenesis in F344 rats treated with 1,2-dimethylhydrazine. J Natl Cancer Int, 57(3), 567-569.

Santarelli, R. L., Pierre, F., \& Corpet, D. E. (2008). Processed meat and colorectal cancer: a review of epidemiologic and experimental evidence. Nutr Cancer, 60(2), 131-144.

Santarelli, R. L., Vendeuvre, J. L., Naud, N., Tache, S., Gueraud, F., Viau, M., Genot, C., Corpet, D. E., \& Pierre, F. H. (2010). Meat processing and colon carcinogenesis: cooked, nitrite-treated, and oxidized high-heme cured meat promotes mucin-depleted foci in rats. Cancer Prev Res (Phila), 3(7), $852-864$.

Sawa, T., Akaike, T., Kida, K., Fukushima, Y., Takagi, K., \& Maeda , H. (1998). Lipid peroxyl radicals from oxidized oils and heme-iron: implication of a high-fat diet in colon carcinogenesis. Cancer Epidemiology Biomarkers \& Prevention, 7(11), 1007-1012.

Sesink, A. L. A., Termont, D. S. M. L., Kleibeuker, J. H., \& Vandermeer, R. (1999). Red meat and colon cancer: the cytotoxic and hyperproliferative effects of dietary heme. Cancer Research, 59(22), 5704-5709.

Sesink, A. L. A., Termont, D. S. M. L., Kleibeuker, J. H., \& VanDerMeer, R. (2001). Red meat and colon cancer: dietary haem-induced colonic cytotoxicity and epithelial hyperproliferation are inhibited by calcium. Carcinogenesis, 22(10), 1653-1659.

Sugimura, T., Wakabayashi, K., Nakagama, H., \& Nagao, M. (2004). Heterocyclic amines: Mutagens/carcinogens produced during cooking of meat and fish. Cancer Sci, 95(4), 290-299.

Truswell, A. S. (2002). Meat consumption and cancer of the large bowel. European Journal of Clinical Nutrition, 56(Suppl. 1), S19-S24.

van der Veere, C. N., Schoemaker, B., van der Meer, R., Groen, A. K., Jamen, P. M., \& Oude Elferink, R. P. J. (1995). Rapid association of unconjugated bilirubin with amorphous calcium phosphate. J. Lipid Res., 36, 1697-1707.

Visek, W. J., \& Clinton, S. K. (1991). Dietary Protein and Cancer. Cancer and Nutrition, 7, 103-124.

Volatier, J. L., \& Dufour, A. (2006). La place de la viande et des produits à base de viande comme aliments-vecteurs dans les apports nutritionnels de la population française. JSMTV, Journées Sciences du Muscle et Technologies des Viandes, 4-5 octobre 2006, Clermont-Ferrand, 11, 55-60.

World Cancer Research Fund, W. (2010). Nutrition, Physical Activity \& Cancer Prevention: Current Challenges, New Horizons. Royal College of Physicians, London, UK. 12-13 Sept. http://www.wcrf.org/cancer_research/cancer_conference.

World Cancer Research Fund, W., \& American Institute for Cancer Research, A. (2007). Food, nutrition, physical activity, and the prevention of cancer: a global perspective. WCRF and AICR, Washington DC, 1-537.

World Cancer Research Fund, W., \& American Institute for Cancer Research, A. (2009). Policy and Action for Cancer Prevention. WCRF and AICR, Washington $D C, 1-400$.

Zhou, L., Haorah, J., Perini, F., Carmella, S. G., Shibamoto, T., \& Mirvish, S. S. (2006). Partial purification from hot dogs of N-nitroso compound precursors and their mutagenicity after nitrosation. J Agric Food Chem, 54(15), 5679-5687. 